\title{
PERSPECTIVA EVOLUTIVA DE LAS TRADICIONALES PAREJAS DE HECHO FRENTE A LAS UNIONES INTERSEXUALES
}

\author{
Elisa Muñoz Catalán \\ Universidad de Huelva
}

http://dx.doi.org/10.5209/rev_NOMA.2014.v43.n3.49283

\begin{abstract}
Resumen.- Analizar el fundamento legal de las tan frecuentes hoy uniones de hecho, el origen de este tipo de prácticas y sus consecuencias para el Ordenamiento jurídico, tomando como punto de partida la regulación que llevó a cabo el Derecho Romano, supone profundizar en un ámbito que puede resultar algo desconocido si tenemos presente que nos encontramos en una época en la que ya se habla de la posible crisis de la familia tradicional.
\end{abstract}

En este sentido, con la realización del presente trabajo pretendemos investigar cómo la ausencia de los presupuestos básicos, especialmente en lo que se refiere a la capacidad jurídica o conubium, incidía en las relaciones extramaritales y cuál fue, en suma, la razón de ser de las prohibiciones al llamado desde la Roma clásica como iustum matrimonium, frente al matrimonio romano legal y con plenos efectos.

Motivo por el cual, a lo largo de nuestra intervención, defenderemos seis criterios clasificatorios que nos servirán para agrupar el gran número de uniones extramatrimoniales que se sucedieron, de entre las que cabe destacar: el concubinato, el contubernio, la homosexualidad, el matrimonio incestuoso, simulado o entre ausentes, las uniones con sujetos que carecían de capacidad física, el adulterio o la prostitución; para acabar, en última instancia, con una breve mención a la influencia ideológica que ejercieron los emperadores, el Cristianismo y la nueva normativa sobre las relaciones intersexuales en Europa.

Palabras clave.- matrimonio, uniones de hecho, capacidad, extramarital, intersexuales.

Abstract.- Analyze the legal basis for the frequent today fact unions, the origin of these practices and their consequences for the juridical Order, taking as a starting point regulation of Roman law, mean deepen in an area which may be unknown if we remember that we are in a period in which the potential crisis of the traditional family is defended.

In this sense, with the accomplishment of the writing that follow we pretend to investigate how the absence of the essential requirements, particularly the legal capacity or conubium, impacted on extramarital affairs and what was, in short, the reason of the prohibitions for the called from classical Roman legal as iustum matrimonium, against the roman marriage with full effects.

Reasons for applying, throughout our intervention, we will defend six classificatory criteria to be used to group the great number of extramarital unions that existed, among which include: concubinage, illegal cohabitation, homosexuality, incestuous, simulated or between absent marriage, the unions with subjects who lacked physical capacity, adultery or prostitution; to finish, ultimately, with a brief mention of the ideological influence of the different emperors, the Christianity and the new regulations on intersex relations in Europe.

Keywords.- marriage, fact unions, capacity, extramarital, intersexuals. 


\section{INTRODUCCIÓN}

A principios de noviembre de 2013, Alemania se convirtió en el primer país europeo en reconocer legalmente la existencia de un tercer sexo o género entre aquellos sujetos intersexuales considerados como tal porque, desde un punto de vista médico, presentaban ambigüedad genital o poseían lo que se conoce como un sexo indiferente, esto es, que tanto física como biológicamente mostraban caracteres propios del sexo femenino y del masculino ${ }^{1}$. De hecho, la normativa recientemente aprobada por el país germano surgió tras los resultados de un estudio llevado a cabo previamente por el Consejo Alemán de Ética que determinó que, aún hoy y en pleno siglo $\mathrm{XXI}$, la legislación de la Unión Europea no garantiza expresamente el goce o disfrute de los derechos humanos y fundamentales de las personas intersexuales en condiciones de igualdad respecto a quienes no lo son; motivado, quizás, por el rechazo y marginación social que los sujetos con dicha deformidad han sufrido a lo largo de la Historia pues desde la antigua Roma se prefirió emplear la voz hermafrodita en lugar del moderno término intersexual ya que el primero aludía a la unión de Hermes y Afrodita, dioses griegos representativos de lo masculino y lo femenino, o en última instancia las tradicionales lagunas legislativas en esta materia igualmente se pueden deber a la inexistencia de una definición jurídica que identifique de forma homogénea y englobando todos los supuestos a estos seres humanos de sexo algo indefinido.

Es en este punto en el que entendemos que tiene la razón de ser el presente trabajo, mediante el que pretendemos ofrecer una aproximación a la gran diversidad de uniones extra-conyugales, esporádicas o meramente sexuales que en Roma no cumplían con los presupuestos esenciales de capacidad física y de capacidad jurídica o conubium como para considerarlas un matrimonio romano legal, eficaz y con plenos derechos o un iustum matrimonium a efectos del Derecho Romano clásico y de mayor esplendor ${ }^{2}$; aportando, a tal efecto, una serie de criterios o principios que nos pueden ayudar a sistematizar las cerca de treinta relaciones esporádicas de carácter extramatrimonial diferentes que se dieron durante la existencia del Orden romano.

Teniendo presente, en todo caso, que no resulta fácil conceptualizar ni el propio matrimonio pues para su definición legal originaria debemos acudir a las escasas fuentes jurídicas ${ }^{3}$ que de algún modo sí aluden a esta institución

\footnotetext{
1 Para un estudio detallado de estos conceptos médicos, vid entre otros, AGRAMONTE MACHADO, A., "Tratamiento quirúrgico de los genitales ambiguos: fundamentos e implicaciones psicológicas y sexuales", Revista Cubana de Endocrinología, v. 17, III (2006) [En línea]: http://scielo.sld.cu/scielo.php?script=sci_arttext\&pid=S1561-29532006000300004; UGARTE, F. y SEPÚLVEDA, C., "Estudio del recién nacido con ambigüedad genital y gónadas palpables", Revista Chilena de pediatría, v. 78, VI (2007), pp. 578-583 [En línea]: http://www.scielo.cl/pdf/rcp/v78n6/art02.pdf

${ }^{2}$ En cuanto a la importancia de la etapa clásica por su influencia en la institución matrimonial, vid. por todos, SCHULZ, F., Derecho Romano clásico, Barcelona, 1960, p. 108 ss.

${ }^{3}$ Cfr. D. 23,2,1 (Mod. 1 reg.); Cfr. IJ. 1,9,1.
} 
familiar, configurándola como la unión consentida y libre de dos personas de sexo distinto, capaces desde un punto de vista físico y jurídico, con la intención de formar un consorcio continuado y recíproco para toda la vida, siempre que se respetase: por una parte, el elemento objetivo u honor matrimonii que significaba una convivencia exteriorizada entre los contrayentes; y de otro lado, el elemento subjetivo e intencional calificado como la affectio maritalis que representaba la intención o voluntad mutua y perpetuada de los cónyuges para tenerse como marido y mujer. A sensu contrario podemos decir que cuando no se daban dichos requisitos y, de forma paralela al vínculo marital, surgían las antes mencionadas uniones extramatrimoniales de carácter puramente ocasional, parejas de hecho o relaciones sine conubio cuyo número fue aumentando progresivamente en el Imperio romano ante la dificultad para obtener el conubium, ius conubii, la capacidad jurídica 0 , en términos generales, el derecho al matrimonio. Por tal razón y, siguiendo los estudios llevados a cabo por $O$. Robleda ${ }^{4}$, a lo largo de nuestra exposición demostraremos cuáles son esos elementos definitorios de las relaciones sexuales conformadas a pesar de la inexistencia del conubium y de la capacidad física o natural de las esposos.

Señalando, en primer lugar, que debía tratarse de uniones inestables o esporádicas cuya consideración jurídico-social dependiera de la condición jurídica de los sujetos que se unían, como era el caso del concubinato, el contubernio, las relaciones homosexuales, los matrimonios contra mandata ${ }^{5}$, entre ausentes o las uniones entre patricios y plebeyos; de igual forma, extrafamiliar eran aquellas relaciones en las que no existía la capacidad física de las partes ya fuesen castrados, esterilizados, ancianos, dementes, locos (furiosus) o matrimonios contraídos por menores de edad.

En tercer término, estas parejas de hecho se podían caracterizar por no respetar los vínculos familiares existentes, como en el supuesto de los matrimonios incestuosos, el ligamen, la consanguinidad o los matrimonios contraídos sin que la viuda respetase el tempus lugendi. Se consideraban relaciones extra-conyugales, a la postre, aquellas otras en las que no existía un consentimiento mutuo libremente prestado entre hombre y mujer o éste estaba de algún modo viciado, aludiendo así a los matrimonios simulados, por miedo o por violencia, las uniones maritales viciadas por error o dolo, y los matrimonios informes dada la ausencia de formalidad o solemnidad en la que habían sido celebrados.

Finalmente, detendremos nuestra atención en aquellas otras uniones de hecho que tampoco respetaban el principio monogámico propio del iustum matrimonium como en los casos de adulterio, bigamia, prostitución o lenocinio. A estos supuestos se le añadirán, desde época postclásica y justinianea, otros

\footnotetext{
${ }^{4}$ ROBLEDA, O., El matrimonio en Derecho Romano. Esencia, requisitos de validez, efectos, disolubilidad, Roma, 1970, p. 276.

${ }^{5}$ En cuanto al carácter de extramatrimonial en los distintos tipos de matrimonium iniustum y, en especial, en los matrimonios contra mandata, vid. por todos, CUENA BOY, F., "La prohibición del funcionario con mujer de la provincia en la que sirve. Derecho Romano y Derecho castellano", en LÓPEZ-ROSA, R. y DEL PINO-TOSCANO, F. (Eds.), El Derecho de Familia. De Roma al Derecho Actual, Huelva, 2004, pp. 99-108.
} 
casos que claramente reflejaban la influencia del Cristianismo en el Imperio romano, como eran las relaciones contra legem entre un tutor y su pupila, el rapto, las uniones con colonos de baja condición social, la disparidad de religión entre judíos y cristianos, los vínculos conformados existiendo un parentesco espiritual, y también el orden sagrado o el voto de castidad como límites a tales uniones.

\section{HACIA UNA SISTEMATIZACIÓN JURÍDICA QUE INTEGRE LA HETEROGENEIDAD DE UNIONES EXTRAMATRIMONIALES EXISTENTES DESDE ROMA}

Como adelantábamos anteriormente, a continuación presentamos un elenco de las relaciones extra-conyugales que surgieron en Roma y que se caracterizaron todas ellas por la falta de conubium o ausencia del derecho al matrimonio, así como por no cumplir con el resto de requisitos clásicos exigidos como para considerarlos un iustum matrimonium dada la incapacidad jurídica que las partes presentaban; lo que, sin lugar a dudas, conllevaba la existencia de otro tipo de relaciones menos reguladas o incluso ilícitas o prohibidas, desde la etapa clásica hasta la postclásica o justinianea con la llegada del Cristianismo y su posterior influjo en emperadores romanos como Constantino I o Justiniano.

Para comprender el fundamento jurídico de este tipo de prácticas esporádicas debemos partir de las siguientes premisas generales. En primer término señalar que como las relaciones sine conubio fueron numerosas, se plantea la dificultad de aportar una categorización legal completa de todas ellas pues las fuentes son escasas y regulan la materia de manera fragmentaria o parcial, de tal forma que determinadas uniones extramaritales sólo se abordaron desde el Derecho Postclásico y con el advenimiento de las ideas cristianas, obviándose de este modo el periodo clásico o preliminar. De lo anterior se deriva el hecho de que, aun cuando se ha pretendido abordar esta materia desde diferentes ámbitos, creemos que tampoco se ha sabido ofrecer una clasificación clara y sistemática de todas ellas, razón por la cual, nuestra tarea consiste en tratar de integrar e interpretar los textos y analizar su evolución clásica hasta la presencia de Justiniano en el Imperio romano.

En tercer lugar cabe recordar que, a lo largo de nuestro estudio, hemos hecho uso de los términos impedimento, prohibiciones, restricciones o limitaciones al matrimonio justo de forma indiferente, aludiendo en general a su significado literal, esto es, como meros obstáculos o inconvenientes a contraer un matrimonio conforme a las reglas del Derecho Romano, dada la ausencia de conubium y siempre teniendo en cuenta el origen canónico de dicho vocablo.

Todas esas uniones extra-conyugales venían delimitadas, a su vez, por dos categorías genéricas con efectos jurídicos similares entre sí pero distintos de los matrimonios romanos clásicos; nos referimos, en cualquier caso, al matrimonio ilegítimo inexistente (matrimonium iniustum non potest) considerado como tal por haber sido contraído en defecto un consentimiento mutuo entre las partes, englobando el matrimonio del demente, el matrimonio simulado o el matrimonio por miedo, así como aludimos al matrimonio ilegítimo ineficaz (matrimonium iniustum nullum) por contravenir las exigencias legales y por no 
contar con presupuestos tan esenciales como fue el conubium, agrupando en este segundo supuesto el matrimonio informe, el matrimonio contra mandata y las uniones ilícitas con mujer adúltera.

Pues bien, bajo las premisas anteriores, pasamos a detallar cuáles son esos seis criterios $^{6}$ básicos que hemos utilizado con la intención de aglutinar y ordenar los caracteres propios de cada una de esas uniones no matrimoniales y contra legem que se dieron en Roma: a) la consideración jurídico-social ${ }^{7}$ : en efecto, en el siguiente apartado de nuestro trabajo se analizarán una serie de prácticas que tenían como punto en común la consideración de los que se unían ilícitamente, por lo que éste nos sirve como primer principio clasificatorio. Concretamente, a este primer grupo pertenecen las relaciones extra-familiares por concubinato, contubernio, las uniones entre homosexuales ${ }^{8}$, aquellas otras formadas entre patricios y plebeyos, los matrimonios contra mandata, los vínculos fuera del matrimonio con persona deportada, desterrada a una isla desierta u oasis, o ausente por causa del servicio militar; b) el principio de la capacidad física o natural de las partes: este segundo criterio que hemos manejado, por su lado, tenía en cuenta si mediaba o no la capacidad física de los que se unían, por lo que dedicaremos otro epígrafe de nuestra investigación a detallar las relaciones sine conubio con castrados, esterilizados, impotentes o ancianos, y aquellas otras uniones carentes de la capacidad jurídica necesaria por la falta de capacidad mental y demencia del loco o furious; c) conforme a los vínculos familiares existentes: como tercer criterio y, bajo el mismo epígrafe anterior, analizaremos las uniones extra-conyugales por incesto, ligamen, consanguinidad, así como las relaciones sine conubio de la viuda que no hubiera respetado el tiempo de luto o tempus lugendi dada la posible mezcla de sangres que de ello se podía derivar.

En último apartado de nuestro estudio, detallaremos de forma conjunta los tres criterios que faltan que nos servirán de cierre al presente trabajo: d) el criterio que tiene en cuenta la existencia o no de consentimiento por parte de los sujetos que se unían: señalándose específicamente los matrimonios simulados, los matrimonios por miedo o los matrimonios informes; e) a lo que se añade, en quinto lugar, el criterio relativo al respeto al matrimonio monogámico y a los principios de la moral romana: diferenciándose entre el adulterio, la prostitución y el lenocinio; f) y finalmente, según la influencia ideológica que ejercieran los

\footnotetext{
${ }^{6}$ Sobre el fundamento o razón de ser de los seis criterios clasificatorios defendidos por la autora de este trabajo y para un estudio más detallado de los impedimentos de los que derivan, vid por todos, MUÑOZ CATALÁN, E., "Las uniones extramatrimoniales ante la falta de conubium: Fundamento jurídico de los impedimentos matrimoniales en la Roma clásica", en Arias Montano: Repositorio institucional de la Universidad de Huelva. Colección de Tesis Doctorales, 2013, pp. 338-736 [En línea]: http://rabida.uhu.es/dspace/bitstream/handle/10272/6457/Las_uniones_extramatrimoniales.pdf? sequence $=2$

${ }^{7}$ En general, refiriéndonos a la condición social como causa impeditiva del matrimonio en Roma, vid. por todos, DE ROBERTIS, F. M., "La condizione sociale e gli impedimenti al matrimonio nel Basso Imperio", Annali Bari, IV (1939), p. 45 ss.

${ }^{8}$ En materia específica de homosexualidad e impotencia, nos remitimos a los resultados mostrados en una investigación anterior de la autora de este trabajo, vid. MUÑOZ CATALÁN, E., "La impotencia generandi en el matrimonio romano homosexual", FORO. Revista de Ciencias Jurídicas y Sociales, Nueva Época , vol 16, II (2013) [En línea]: http://revistas.ucm.es/index.php/FORO/issue/current
} 
emperadores romanos: veremos el criterio que distingue entre aquellas relaciones prohibidas por Augusto por ir contra la legislación matrimonial, como por ejemplo las uniones entre senadores y mujeres turpes, y aquellas otras limitadas por el emperador Constantino y más tarde por Justiniano, como los casos de parentesco espiritual, el orden sagrado o el voto de castidad.

De forma comparativa y en aras a complementar o justificar nuestra sistematización, nos interesa examinar brevemente la clasificación ofrecida por J. C. Ghirardi ${ }^{9}$, quien de forma general enumeró los distintos tipos de uniones extra-familiares existentes Roma; precisamente, el autor las califica directamente de uniones sexuales, actos sexuales contra natura y relaciones carnales consentidas llevadas a cabo al margen del matrimonio legítimo, en las que el sujeto activo generalmente era un hombre y el sujeto pasivo variaba considerablemente. En este sentido, diferencia unos diez tipos de prácticas sexuales ilegales que pasamos a nombrar: el adulterio, siempre que un hombre tuviese relaciones consentidas con una mujer casada pues ello estaba penado por la Ley Iulia de Adulteriis Coercendis (1ㅇ); el estupro, cuando un hombre tenía relaciones sexuales consentidas con una mujer viuda o una doncella de similar o superior posición social a la suya $\left(2^{\circ}\right)$; el estupro con otro hombre $\left(3^{\circ}\right)$; $y$, en cuarto lugar, cita al concubinato producido cuando un hombre tenía relaciones sexuales consentidas y estables con una mujer de baja extracción social o una liberta, con la cual, carecía de ius connubium y le era imposible por ese motivo contraer matrimonio y tener affectio maritalis. Sobre este último, el profesor aclara que se trataba de una relación de rango inferior al matrimonio pero lícita, si bien: "A partir del advenimiento del Cristianismo se tendió a mirarlo con disfavor, dado que la Iglesia primitiva enseñaba que la única manera de vida en común posible era dentro de una familia, fundada sobre la base de la unión matrimonial. Como el concubinato se salía de este molde, fue despreciado, además de considerárselo un pecado que ofendía el sexto mandamiento" (4ํㅜ).

A lo anterior se añaden el resto de relaciones que comprenden la sistematización defendida por este autor, a saber: la prostitución, pero matizándose que cuando un hombre alternase con prostitutas éste no cometía acto reprobable alguno a efectos del Derecho Romano ni era causa de divorcio (5); la violación o rapto si un hombre sometía por la fuerza a una mujer o a otro hombre contra la voluntad de éstos, ya que era autor responsable de violación, si bien J. C. Ghirardi ${ }^{10}$ nos comenta que: "Durante mucho tiempo no existió legislación específica que se refiriese a la violación, de manera que solamente debe haber cabido la posibilidad de perseguirla conforme la forma y penalidades establecidas para el delito de iniuria" (6ํ); el acoso sexual, cuando un hombre sin llegar al acceso carnal provocaba a una mujer libre cometiendo el delito de iniuria y normalmente violando, a su vez, el Edicto de Adtemptata Pudicitia $^{11}$ dado el atentado al pudor que perpetraba $\left(7^{\circ}\right)$; cometían incesto

\footnotetext{
${ }^{9}$ GHIRARDI, J. C., "Regulación jurídica de las conductas sexuales extramatrimoniales en el Derecho Romano", RGDR, V (2005), pp. 9, 44-49.

${ }^{10}$ GHIRARDI, J. C., "Regulación jurídica de las conductas sexuales...", op. cit., pp. 35-36.

${ }^{11}$ En cuanto al alcance de este Edicto en materia de acoso, vid. por todos, BRAVO BOSCH, M. J., "Algunas consideraciones sobre el Edictum de Adtemptata ad pudicitia", en AAVV., Actas del Il Congreso Iberoamericano de Derecho Romano, Murcia, 1998, pp. 41-53; DELAPUERTA
} 
aquellos hombres que mantenían relaciones sexuales con su pupila o con una parienta en grado próximo de parentesco, conllevando la nulidad del matrimonio contraído y sanciones penales $\left(8^{\circ}\right)$; contubernio pues en esta unión intervenían esclavos, ya fuesen éstos entre sí o con alguna otra persona libre, pero no incurrían en conducta reprochable alguna, y tal actitud tampoco justificaba que su mujer solicitase el divorcio o le repudiase. Como nos advierte el profesor si el esclavo era ajeno, hubiera o no consentimiento de ellos, incurría para con el dueño de los siervos en el delito de daño y caía dentro de las previsiones de la Ley Aquilia, siendo pasible también de que se ejercitase contra él la acción pretoria de corrupción de esclavo (9ํ); sobre los casos de homosexualidad femenina, finalmente, cabe decir que las uniones lésbicas entre mujeres no fueron reguladas expresamente por el Derecho Romano, si bien el autor ${ }^{12}$ concluye su intervención admitiendo que ello: "No implica que no existiesen, y sin perjuicio de que las mismas, si resultaban escandalosas, podrían dar lugar a la correspondiente acción de injurias, por parte del o de los ofendidos" $\left(10^{\circ}\right)$.

Dejando al margen los distintos principios clasificatorios que hemos dado a conocer, cabe recordar las dos dificultades fundamentales que se plantean en este ámbito, pues salvo instituciones más reguladas como el concubinato, el contubernio, o las uniones introducidas por la legislación matrimonial de Augusto, no contamos con fuentes jurídicas o literarias suficientes que nos ayuden en la tarea de investigar esas uniones extra-familiares $y$, por ende, debemos acudir a las diversas interpretaciones textuales y opiniones doctrinales existentes al respecto para poder entender el verdadero alcance de cada relación. $Y$, la segunda dificultad a la que hacemos frente, es que las últimas uniones extra-conyugales a causa de la tutela, el rapto, el colonato, la disparidad de religión entre judíos y cristianos, el parentesco espiritual y por orden sagrado o voto de castidad, serán objeto de estudio desde su existencia en la Roma postclásica dada la escasez de textos anteriores que regulen dichos supuestos, eliminándose de este modo cualquier mención al periodo clásico anterior o de mayor esplendor.

Por lo expuesto, no sólo la falta de conubium determinó desde época clásica el nacimiento de una prohibición matrimonial sino que a este requisito de carácter negativo se le podían unir otros también importantes, como fueron, la ausencia de capacidad física o natural entre las partes, la inexistencia de un consentimiento recíproco entre los contrayentes o el incumplimiento del principio monogámico, entre otros. Lo que tendrá su reflejo en los tipos de uniones extramatrimoniales sine conubio que presentamos y desarrollamos en las siguientes líneas de nuestro trabajo de investigación.

\section{LA CONSIDERACIÓN SOCIAL ANTE EL CONCUBINATO, CONTUBERNIO, LA HOMOSEXUALIDAD, LOS MATRIMONIOS CONTRA}

MONTOYA, D., Estudio sobre el Edictum de Adtemptata Pudicitia, Valencia, 1999; GHIRARDI, J. C., "Regulación jurídica de las conductas sexuales...", op. cit., pp. 38-39.

${ }^{12}$ GHIRARDI, J. C., "Regulación jurídica de las conductas sexuales...", op. cit., p. 10. 


\section{MANDATA, POR DEPORTACIÓN, INTER ABSENTES O EN LAS RELACIONES ÍNTIMAS ENTRE PATRICIOS Y PLEBEYOS}

Comenzamos este apartado de nuestro trabajo tomando como punto de referencia el primer criterio que hemos defendido previamente, es decir, aquel relativo a la consideración jurídica y social de los futuros esposos pues el mismo nos sirve hoy para poder articular las uniones extramatrimoniales sine conubio que se englobaban bajo esa distinción. En este punto, podemos confirmar que el concubinato se conformaba como la relación más frecuente en el Imperio pues presentaba un carácter estable y era admitido socialmente, si bien su reconocimiento fue variando a lo largo de las distintas etapas de vigencia del Derecho Romano; pasando de ser una figura de hecho reconocida por el Derecho Clásico, hasta considerarse como una institución jurídica con plenos efectos ya desde época postclásica con los emperadores romanos cristianos y, especialmente, en lo que respecta al emperador Justiniano.

Concretamente, esta primera relación fáctica o de hecho se producía libremente entre un hombre y una mujer cuando no existía una mutua intención de estar vinculados legalmente a través del matrimonio y, en general, faltaban los requisitos esenciales siendo la ausencia de la affectio maritalis o el consensus entre las partes el elemento que marcaba la diferencia entre el matrimonio y el concubinato; por tal razón, se han venido calificando de uniones paramatrimoniales y de uniones o parejas de hecho por ser similares o a imitación del matrimonio romano aun faltando el elemento volitivo, así como por estar perfectamente diferenciadas de las uniones transitorias o voluptuosas, y de las meras relaciones sexuales esporádicas.

En este ámbito, hemos partido de la etapa clásica puesto que es cuando la legislación matrimonial del emperador Augusto comenzó a regular por escrito el concubinato, otorgándole ciertos efectos jurídico-sociales, a modo de ejemplo, cabe citar cómo la Lex lulia de adulteriis castigaba como delito las uniones sexuales producidas fuera del matrimonium y las consideraba adulterium o strupum, a la vez que ofrecía toda una sistematización de aquellas mujeres de clase social inferior con las que se podía tener relaciones sin incurrir en las penas previstas para el adulterio o estrupo, refiriéndonos a las meretrices, las actrices condenadas en juicios públicos, las esclavas o las libertas ${ }^{13}$. Aunque no tenían honestas, lo cierto es que con estas mujeres era posible la unión extra-conyugal estable por no ser penalmente punible.

Sobre la evolución de esta figura, hemos concluido que si bien Constantino I quiso proteger las uniones legales y honestas ordenando su conversión en matrimonio con la finalidad de obstaculizar el concubinato, lo cierto es que dicho emperador no alcanzó su objetivo y este tipo de relaciones extramaritales comenzó a adquirir desde entonces una mayor importancia aumentando su número de forma considerable; destacándose que el concubinato fue reconocido, posteriormente, por el emperador cristiano Justiniano como una inaequale coniugium, esto es, una unión lícitamente contraída y monogámica pero de carácter inferior al matrimonio, requiriéndose la misma edad que para el matrimonio y sujetándose a los mismos impedimentos de parentela consanguínea, por adopción o afinidad. En consecuencia, a diferencia de lo que ocurrió desde época clásica con Augusto, el emperador Justiniano hizo más fácil el acceso al matrimonio legalmente conformado, por lo que las uniones concubinarias fueron desapareciendo paulatinamente en el Imperio romano.

En segundo término, hemos incluido dentro de ese primer principio el contubernio ya que desde la etapa clásica se conformó como un tipo frecuente de relación sine conubio, de carácter inestable y con un reconocimiento más social que jurídico que se producía entre esclavos, entre una persona libre y un esclavo, ampliándose este segundo supuesto al caso en el que el cónyuge que había contraído un matrimonio iustum caía en cautiverio y se hacía servus; sin embargo, conviene matizar que en la última etapa de la Historia de Roma el emperador Justiniano derogó toda relación inestable y carente de conubium entre eslavos o personas libres y esclavos favoreciendo, de este modo, los matrimonios legítimos entre esclavos y mujeres libres con la intención de que los súbditos del emperador adquiriesen la libertad $^{14}$.

${ }^{13}$ D. 25,7,1,1 (Ulp. 2 ad Leg. Iul. et Pap.): Cum Atilicino sentio et puto solas eas in concibinatu habere posse sine metu criminis, in quas strupum non committitur.

${ }^{14} \mathrm{M}$. FALÇAO, Las prohibiciones matrimoniales de carácter social en el Imperio Romano, Navarra, 1973, p. 79. El profesor Falçao finaliza este apartado referido al Derecho Justinianeo, 
Mención especial requiere el alcance jurídico de otra de las uniones extra-conyugales sine conubio que también hemos encuadrado en función de la consideración jurídico-social de las partes, aludimos a la homosexualidad y a las relaciones lésbicas. Dada la influencia de la cultura griega que sufrió Roma durante la etapa republicana, no es de extrañar el gran número de relaciones ilícitas que se produjeron entre personas del mismo sexo y que tenían los mismos órganos sexuales ${ }^{15}$, y cuyo fin último no era la procreación sino la mera satisfacción sexual y el placer, siempre teniendo presente que existía una clara incapacidad física para contraer matrimonio romano válido, dado que en este tipo de prácticas las dos partes compartían un mismo género u órganos sexuales. Con el emperador Augusto, estas experiencias sexuales continuaron ejercitándose aumentando el número de ciudadanos bisexuales; sin embargo, las relaciones homosexuales entre mujeres se consideraron la peor de las depravaciones, calificándose en los textos literarios de uniones lésbicas contra natura y criminales ${ }^{16}$.

Referente a los matrimonios contra mandata, en cuarto lugar, decir que se trataba de un tipo de matrimonio nullum e ineficaz dada la falta de voluntad recíproca de las partes de formar un iustum matrimonium, que en época clásica lo conformaban aquellas uniones carentes de ius conubii por haber sido contraídas entre magistrados, funcionarios o soldados que ejercían su profesión u oficio en las provincias y aquellas mujeres nacidas o domiciliadas en dicho lugar. Entendemos que el fundamento de la ausencia del derecho al matrimonio en estos supuestos y el nacimiento de una unión extramarital por razón del cargo público del varón, tanto en época clásica como posteriormente, se encuentra en primer lugar en tratar de salvar la libertad matrimonial de la mujer domiciliada o nacida en dicha provincia ante la posibilidad de que algún funcionario tratase de aprovechar su cargo para imponerle el matrimonio ${ }^{17}$, así como lo anterior también se debía a un intento por evitar que el matrimonio del officium gerens con mujer de familia prestigiosa de la provincia tuviese como finalidad acabar con su profesión. Como consecuencia de dicha prohibición los matrimonios contra mandata fueron nulos 0 jurídicamente inexistentes haciéndose sólo legítimo tras cesar el cargo, por lo que sus hijos tenían la consideración jurídica de ilegítimos.

En cuanto a los matrimonios por deportación, subrayar que ese destierro impedía la formación de un matrimonio romano válidamente constituido debido a la estancia involuntaria del desterrado a una isla u oasis con la consiguiente pérdida de los derechos de ciudadanía y, en caso que existiera una relación entre el deportado a una isla y una mujer libre, esta unión sería calificada como extramatrimonial y sine conubio por razón de la expatriación. Concretamente, en la etapa clásica la deportación suponía un obstáculo al iustum matrimonium no sólo por la falta de los derechos propios atribuidos a los ciudadanos romanos sino por la ausencia del ius conubii, pero desde la llegada al poder del emperador Constantino I y luego con Justiniano, este exilio comenzó a no disolver el vínculo marital dejando de ser causa de impedimento si ya había sido contraído previamente ${ }^{18}$.

Por lo que respecta al matrimonio inter absentes a causa del servicio militar hemos concluido que, hasta finales del siglo II d.C., el cumplimiento del servicio militar impedía el matrimonio romano legalmente contraído al entenderse que de esta manera se mantenía la disciplina en el ejército; no obstante lo anterior, los escasos testimonios con los que contamos nos llevan a no admitir este impedimento como tal, fundamentando dicha tesis negativa en el hecho de que en época clásica los soldados podían continuar con su matrimonio si estos habían sido contraídos antes de ser reclutados en el servicio militar o incluso formar uno nuevo, siempre que no fuese con mujeres oriundas o domiciliadas en la provincia donde prestasen el servicio. Desde tiempo postclásico, el emperador Constantino I (año 337 d.C.) trató de romper con la tradición clásica de restringir las posibilidades que tenía la uxor de contraer un nuevo matrimonio en el supuesto

señalando que: "En resumen: No hay, ciertamente, matrimonio entre persona libre y otra esclava; pero, con tal que el consorte esclavo adquiera la libertad, existe matrimonio como entre ingenuos".

${ }^{15}$ LILJA, S., Homosexuality in Republican and Augustan Rome, Helsinki, 1983, p. 15 ss.

${ }^{16}$ GHIRARDI, J. C., "Regulación jurídica de las conductas sexuales...", op. cit., pp. 9-10.

${ }^{17}$ Cfr. D. 23,2,63 (Pap. 1 definit.).

${ }^{18}$ CJ. 5,16,24,1; Cfr. Nov. 22,13. 
de ausencia del marido a causa del servicio militar, pues ya la mujer podía unirse en segundas nupcias sin caer en adulterio y sin que ello le supusiera la pérdida de la dote; ello era posible si se cumplían dos requisitos esenciales que evitaban la calificación de estos matrimonios como clandestinos, esto es, que hubieran transcurrido al menos cuatro años sin tener noticia de su marido y sin posibilidad de habere iudicium, así como hacía falta notificar al dux del marido su intención de contraer un nuevo matrimonio. Pues bien, como demostró B. Biondi ${ }^{19}$, se trataba de un derecho singular para buscar la seguridad de la muerte del primer marido.

Cerrando este primer criterio clasificatorio hemos aludido, a la postre, a las uniones entre patricios y plebeyos justificando su inclusión en el hecho de ser dos clases sociales muy diferenciadas que, al final, consiguieron contraer un matrimonio libre; en cuanto a su reconocimiento desde los orígenes del Imperio, decir que si bien la Ley de las XII Tablas había prohibido específicamente el ius conubii entre ambos órdenes sociales por considerarlas relaciones inhumanas, lo cierto es que las luchas patricio-plebeyas hicieron que a partir de mediados del siglo V a.C. (445 a.C.) con la Rogatio Canuleia del tribuno Canuleyo, se consiguiera que el gobierno patricio aceptara el derecho al matrimonio y la validez de las uniones entre patricios y plebeyos, concediéndoseles el ius conubii y aceptándose la ausencia de limitaciones legales a las uniones maritales. En todo caso, podemos concluir admitiendo que desde el año 445 a.C. patricios y plebeyos pudieron contraer matrimonio por la Lex Canuleia, pero no se sabe con certeza si fueron muchas las uniones maritales legalmente conformadas o, por contra, desde finales de la Monarquía y principios de la República disminuyeron; lo que sí podemos confirmar es que desde tiempo clásico y, especialmente en época postclásica, estos vínculos fueron desapareciendo dado que apenas contamos con textos que regulen dicha cuestión.

\section{VÍNCULOS FAMILIARES, RELACIONES INCESTUOSAS O MEZCLA DE SANGRE}

El siguiente criterio que hemos tomado como referencia para categorizar estas prácticas sexuales es el de las uniones extra-conyugales sine conubio en razón de la capacidad física o natural de las partes. En primer lugar, hemos reparado en el supuesto de los castrados (castrati), esterilizados (spadones) y ancianos (senes) quienes en principio presentaban cierta impotencia para engendrar y, por ese motivo, tenían limitado su derecho a contraer matrimonio legítimo en Roma; en estos casos existía cierta incapacidad física que obstaculizaba la validez del matrimonio romano clásico pues recordemos que el matrimonium iustum exigía la capacidad natural, la capacidad jurídica, la convivencia marital, y una intención recíproca y continuada de vivir en comunidad para perpetuar la especie ${ }^{20}$.

Por último, nos hemos planteado si durante el Derecho Clásico existió este impedimento o nació con el emperador Justiniano, dado que ciertos textos de la Compilación justinianea reflejan la impotencia de los castrati mientras que otros pasajes aluden a los estériles o naturalmente incapaces ${ }^{21}$, concluyendo a tal efecto que si bien estas limitaciones al matrimonio surgieron durante la época clásica, su regulación legal expresa aparece con Justiniano quien consideraba como impotentes y, por ende en ausencia de conubium, a los castrati pero no así a los estériles o naturalmente incapaces generandi.

\footnotetext{
${ }^{19}$ BIONDI, B., II Diritto Romano cristiano III, Milano, 1954, p. 154.

${ }^{20}$ Cfr. D. 23,2,1 (Mod. 1 reg.); Cfr. IJ. 1,9,1.

${ }^{21}$ DANILO DALLA, L., "L'Incapacità sessuale in Diritto Romano", en Seminario giuridico della Università di Bologna, LXXVI, Milano, 1978, pp. 246, 250 y 288.
} 
Asimismo, hemos reunido en este segundo principio las relaciones del furiosus, el mente captus y el demens. Hacemos referencia, en términos generales, a la persona demente que había sido privado de juicio por razón de su enajenación mental, por lo que esa ausencia de capacidad natural hacía que el individuo se viese afectado por una incapacidad de obrar absoluta y le llevara a una verdadera enfermedad que le impedía unirse maritalmente ${ }^{22}$; de hecho, si temporalmente recobraba el juicio, el Derecho Romano entendía que estaba capacitado para realizar ciertos actos jurídicos pero no para contraer matrimonio, pues este derecho requería la plena capacidad física y jurídica de las partes en el momento de contraer el vínculo marital ${ }^{23}$. En cuanto a la evolución jurídica de estas prácticas sexuales, decir que en el Derecho Justinianeo se restringió este concepto al demente con momentos de lucidez, frente al demens o mente captus afectado de locura permanentemente y, por esto, solamente tenía capacidad legal en los conocidos como intervalos lúcidos, es decir, cuando temporalmente recobraba la salud mental.

Sobre el matrimonio de la menor en Roma, partimos de la premisa general de que uno de los fines principales del matrimonio romano era la procreación por lo que, en principio, no podían contraerlo aquellas personas que no hubiesen alcanzado la pubertad por carecer de la madurez sexual suficiente para tener descendencia; sin embargo, se ha venido añadiendo ${ }^{24}$ la posibilidad de que la mujer contrajese matrimonio incluso antes de los doce años que marcaban la pubertad, fijándose el límite mínimo de los siete años de edad si era viri potens, es decir, capaz de soportar físicamente el ser poseída por un hombre.

De otro lado y, ya centrándonos en el tercer criterio clasificatorio relativo a los vínculos familiares existentes como límite al matrimonio romano, señalar el caso de los matrimonios incestuosos y clandestinos entre parientes. En este sentido cabe resaltar que el pueblo romano, según el propio R. Astolfi ${ }^{25}$, rechazó de forma absoluta las relaciones entre parientes anulando el matrimonio incestuoso e imponiendo penas al que se hubiera unido en un matrimonio clandestino, como era el caso de la deportatio in insulam, sanción propia de época clásica; de este modo, la ausencia de conubium a causa del parentesco entre los sujetos que formaban una relación afectiva, se configuró en la Roma clásica como una limitación matrimonial en razón del vínculo familiar existente entre hombre y mujer que compartían una misma sangre, hecho que conllevaba la calificación de relación extra-familiar mientras que, por su lado, la legislación postclásica retomó las sanciones contra el incesto y reprimió fuertemente los delitos sexuales y, en particular, en lo que respecta al incesto.

A continuación, hemos examinado el ligamen y la exigencia de divorcio ante el doble vínculo. Pues bien, desde época clásica y en especial en tiempo postclásico, la formación de una segunda relación preexistiendo un matrimonio

\footnotetext{
${ }^{22}$ Centrándonos en el alcance y protección del que padecía una enfermedad mental, vid. por todos, MARTíNEZ DE MORENTíN LLAMAS, M. L., "De la cura furiosi en las XII Tablas, a la protección del disminuido psíquico en el Derecho Actual (A propósito de la STS de 20 de noviembre de 2002)", RGDR, IV (2005), pp. 5, 8 ss.

${ }^{23}$ Cfr. D. 50,17,40 (Pomp. 34 ad sab.).

${ }^{24}$ ASTOLFI, R., Il matrimonio nel Diritto Romano classico, Padova, 2006, p. 238 ss.

${ }^{25}$ ASTOLFI, R., II matrimonio nel Diritto Romano..., op. cit., p. 94 ss.
} 
anterior no disuelto hacía que esa unión fuera considerada como extraconyugal, ilícita y no permitida por el Derecho Romano dado el ligamen que existía con el primer vínculo matrimonial; debemos tener en cuenta que el matrimonio romano fue esencialmente monogámico y la existencia de un vínculo matrimonial no disuelto se entendía como una limitación matrimonial debido a dos motivos fundamentales, como eran, la ausencia de ius conubii entre las partes y la antinaturalidad que suponía la existencia de un doble vínculo, independientemente de la condición o profesión de la persona que pretendía contraer dos matrimonios.

Teniendo en cuenta que el divorcio del primer vínculo dejó de ser libre a partir del Derecho Postclásico y, muy especialmente con el emperador Justiniano, ello hizo incrementar el número de relaciones extra-conyugales sine conubio por existencia de doble vínculo en el Imperio, tal y como se recoge en los textos justinianeos que abordan este impedimento y que literalmente sostienen que el ligamen al menos desde época postclásica impedía el matrimonio ${ }^{26}$. Pues bien, ante esto, hemos concluido nuestra investigación defendiendo que la existencia de un matrimonio anterior sólo constituyó impedimento matrimonial como tal desde época postclásica, cuando el matrimonio estaba basado en un consentimiento meramente inicial.

Dentro de este grupo hemos englobado, en último lugar, el supuesto del tempus lugendi y la mezcla de sangre como prohibiciones matrimoniales a la viuda. Aludimos a aquellas uniones extramatrimoniales sine conubio que se producían cuando la viuda, no respetando el tiempo de luto, había vuelto a contraer un nuevo matrimonio; desde los orígenes del Derecho Romano, existía una imposibilidad para que ésta pudiera contraer un segundo matrimonium iustum antes de los diez meses siguientes a la muerte del primer marido, tratando así de evitar posibles dudas sobre un embarazo posterior y la mezcla de sangre (partus o turbatio sanguinis) y de hecho, desde la etapa clásica, las personas que no respetaban este periodo sufrían una limitación al matrimonio romano justo y sólo podían formar una unión extra-familiar dada la posible mezcla de sangres y la incertidumbre ante una posible paternidad. En cuanto al Derecho Postclásico y el influjo cristiano destacar, por último, que además de exigirse los doce meses o annus lugendi también se requería que esta limitación al iustum matrimonium recayera tanto sobre la viuda como la divorciada ${ }^{27}$.

\section{CONSENTIMIENTO DE LAS PARTES, MORAL ROMANA Y CRISTIANISMO}

En este epígrafe de nuestra exposición, estudiaremos los tres últimos criterios que nos sirven de cierre a la sistematización que hemos llevado a cabo a lo largo de nuestro estudio, detallando aquellas relaciones sine conubio producidas sin consentimiento, no respetando el principio monogámico del matrimonio o aquellas otras que tuvieron lugar por la ideología de los

\footnotetext{
${ }^{26}$ Cfr. IJ. 1,10,6; Cfr. IJ. 1,10,7.

${ }^{27}$ Cfr. Nov. 22,40.
} 
emperadores romanos en cada periodo de la Historia de Roma, en especial, en lo que respecta a la etapa clásica, postclásica y justinianea.

Pues bien, primeramente y dependiendo de si mediaba o no consentimiento de los sujetos, hemos distinguido entre los matrimonio simulados, caracterizándolos como aquellos vínculos contraídos entre personas entre las que no había un consentimiento verdadero como para formar una familia y procrear, sino todo lo contrario, la intención real era la de beneficiarse de las ventajas que se daban a los matrimonios dentro de las Leyes de Augusto ${ }^{28}$. Estas relaciones, también denominadas como matrimonios de complacencia o uniones a cambio de un precio, se consideraban como relaciones extramatrimoniales sine conubio por razón de la simulación y la ausencia de affectio maritales, siendo supuestos de inexistencia jurídica al surgir una discordancia entre las voluntades declaradas por los que se unían y las intenciones que verdaderamente eran queridas; no existiendo, en ningún caso, una pretensión real de convivir en una sociedad conyugal ni una voluntad continuada de formar una familia, lo que finalmente conllevaría al divorcio.

Igualmente, destacamos los matrimonios contraídos por miedo o violencia por tratarse de aquellas uniones cuasi-maritales llevadas a cabo en Roma contra la voluntad de al menos uno de los cónyuges y que, al igual que ocurría en los matrimonios simulados, también se producía una inexistencia del consentimiento efectivo y real pero a causa del miedo o el temor producido por la amenaza y coacción. Este tipo de para-matrimonios por miedo (metus) o por violencia ( vis) se caracterizaba por la fuerza material y física o la violencia externa que había que ejercer para que una de las partes contrajese el vínculo marital, no consistiendo en un mero temor o coacción ${ }^{29}$; a nuestro parecer, el matrimonio romano clásico no podía ser contraído bajo coacción ya que era un derecho que debía ser aceptado libremente, pues la finalidad principal era formar un consorcio para toda la vida y perpetuar la especie, de la misma forma que en tiempo postclásico tampoco fueron válidos dichos matrimonios y se consideraron como no contraídos debido a la concepción del consensus como meramente inicial.

Mención individual requieren los matrimonios viciados por error o dolo pues, en línea con el anterior supuesto, nos encontramos con un tipo especial de matrimonio iniustum considerado como tal por estar viciada o modificada la voluntad de al menos uno de los futuros esposos. El problema principal de estos conocidos como matrimonios por error o matrimonios por dolo son los escasos textos que abordan la materia, pues dificulta la tarea de determinar a lo largo de nuestra investigación cuál es la esencia de este tipo de uniones extramatrimoniales sine conubio en época clásica e impedimentos matrimoniales ya en tiempo postclásico ${ }^{30}$. De esta forma, retomamos los estudios llevados a cabo por R. Astolfi ${ }^{31}$ sobre estas prácticas quien mantuvo

\footnotetext{
${ }^{28}$ En tema de matrimonio romano y, concretamente, sobre la importancia de que existiese una voluntad real de unirse perpetuamente en un consortium omnis vitae, vid. por todos, BIONDI, B., II Diritto Romano cristiano..., op. cit., p. 101.

${ }^{29}$ Cfr. D. 4,2,21,5 (Paul. 11 ad edict.); Cfr. D. 23,2,21 (Terent. Clem. 3 ad Leg. Iul. et Pap.); Cfr. D. 23,2,22 (Cel. 15 dig.).

${ }^{30}$ Cfr. D. 3,2,1 (lul. 1 ad edict.); Cfr. D. 23,2,43,10 (Ulp. 1 ad Leg. Iul. et Pap.).

${ }^{31}$ ASTOLFI, R., I/ matrimonio nel Diritto Romano..., op. cit., pp. 102-103.
} 
que estos matrimonios eran nulos debido al error en la identidad del cónyuge, conformándose en Roma como un claro impedimento al matrimonio legal.

Para acabar, decir que pertenecen también a este cuarto criterio los casos de matrimonios informes. Nos referimos, en general, a una forma ad solemnitatem que cumplía todo matrimonio romano contraído válidamente y que si no se verificaban tales elementos formales, se consideraban ilegítimos, no firmes y carentes de efectos aun cuando no ineficaces ${ }^{32}$; mientras el Derecho Romano arcaico exigía ciertas solemnidades para contraer matrimonium, lo cierto es que ya desde época clásica los vínculos maritales pudieron ser contraídos libremente y de cualquier forma, puesto que el matrimonio romano era un hecho con relevancia social y lo que importaba era la existencia de un consentimiento mutuo continuado, así como la capacidad jurídica y física de los cónyuges $^{33}$.

De otra parte y, aludiendo ahora al quinto criterio clasificatorio que diferenciaba los casos que afectaban a la moral romana y al principio monogámico del matrimonio, hemos distinguido en primer término el supuesto del adulterio y la bigamia. En este sentido, recordar que hemos definido al matrimonio romano como esencialmente monogámico, por lo que no cabría hablar de una tercera persona ajena o un cómplice en dicha relación conyugal, pues desde los comienzos del Imperio romano se rechazaron las uniones maritales bígamas. En la etapa arcaica, el varón que sufría el adulterio por parte de su esposa podía castigarla a través del iudicium domesticum o procedimiento privado excepcional en el que se consultaba al paterfamilias y demás parientes que formaban un consejo de familia; ya con las leyes matrimoniales de Augusto, se sustituyó por el iudicium moribus considerándose el adulterio como una limitación al matrimonio dada la falta de conubium entre los contrayentes para conformar un matrimonio justo, calificándose generalmente como de impedimentum criminis y ante esto, el adulterium pasó a ser un crimen público perseguido a instancias del marido o del padre de la adúltera y también de cualquier ciudadano, si ellos no lo hacían transcurridos dos meses desde el divorcio. En cuanto a su evolución posterior, cabe señalar que no será hasta Constantino I y, especialmente con el emperador Justiniano, cuando este impedimento se establezca como prohibición expresa entre la adúltera y el cómplice por influencia del Cristianismo, extendiéndose incluso hasta después de la muerte del marido y castigándose el adulterio con la pena capital ${ }^{34}$.

Este penúltimo principio también aglutinaría los casos de prostitución y lenocinio, por ser unas prácticas muy habituales en Roma. La Lex Iulia de adulteriis castigaba como adulterium o stuprum toda unión sexual fuera del matrimonio, existiendo diferentes categorías de mujeres con respecto a las cuales era posible tener relaciones sexuales sin incurrir en pena alguna, por lo que se trataba ${ }^{35}$ de aquellas mujeres consideradas probosae o turpes y carentes de honestidad con las que sí se podía contraer concubinato y a las que nunca se les podría denominar materfamilias. Dentro de este grupo nos encontramos, en suma, con las mujeres esclavas (servus), las actrices (scaenica) y las condenadas en juicio público, las adúlteras

${ }^{32}$ Cfr. D. 23,2,2 (Paul. 35 ad edict.); Cfr. D. 23,2,6 (Ulp. 35 ad sab.); Cfr. D. 23,2,18 (Iul. 16 dig.); Cfr. D. 23,2,21 (Terent. Clem. 3 ad Leg. lul. et Pap.); Cfr. D. 23,2,22 (Cel. 15 dig.) ; Cfr. D. 23,2,25 (Mod. 2 reg.); Cfr. D. 23,2,30 (Gai. 2 ad Leg. Iul. et Pap.); Cfr. D. 23,2,35 (Pap. 6 resp.).

${ }^{33}$ Cfr. D. 23,2,1 (Mod. 1 reg.).

${ }^{34}$ Cfr. PS. 2,26,3.

${ }^{35}$ M. FALÇAO, Las prohibiciones matrimoniales..., op. cit., p. 22. 
sancionadas, las mujeres que habían violado la fidelidad matrimonial y las sorprendidas en adulterio, así como las obscuro loco natae, es decir, las hijas de actores o actrices cuyo origen fue oscuro y poco honorable; por último, no podemos olvidar a las libertas, las meretrices 0 amantes (meretrix), las prostitutas (corpore quaestum faciens) o exprostitutas, y las alcahuetas o seductoras (lenas).

Para terminar y, cambiando de tercio, aludimos al sexto y último criterio tomado como referencia para dividir las distintas uniones extra-conyugales, refiriéndonos a aquel que tiene en cuenta la ideología de los emperadores a lo largo de las distintas etapas de la Historia de Roma. Sobre las uniones no consideradas por Augusto como matrimonio secundum Legem Iuliam et Legem Papiam Poppaeam, en primer lugar, hemos retomado la importancia de la Lex Iulia de maritandis ordinibus (18 a.C.) y la Lex Papia Poppaea (9 d.C.) promulgadas por el emperador Augusto con el nombre de Lex lulia et Papia Poppaea, cuya finalidad era restaurar la familia romana sobre la base de las tradiciones para desarrollar una política legislativa que favoreciese tanto las uniones matrimoniales lícitamente contraídas como la procreación; por esta norma, todos los ingenuos salvo los senadores y sus descendientes podían contraer matrimonio con los libertos, eliminando cualquier impedimento al matrimonio originado por la distinta clase o condición social.

Si bien no nos encontramos con fuentes que indiquen el origen de estos impedimentos y, menos aún que defiendan que estas limitaciones naciesen con las leyes matrimoniales de Augusto, nosotros hemos mantenido que la ausencia de conubium relativo y de tipo social se dio en los siguientes supuestos que pasaban a formar parte de las conocidas como uniones concubinarias. En primer lugar, en los matrimonios entre senadores, sus hijos y ulteriores descendientes hasta el tercer grado (hasta los bisnietos), tanto ellos como ellas por una parte y libertinas, personas de teatro o hijos de personas de teatro, artistas o hijas de artistas y prostitutas, por la otra; todo ello para tratar de evitar la mezcla de clases y conseguir que la raza se conservase pura. Con la misma intención de evitar la mezcla de sangre estaban vetados los vínculos contraídos entre ingenuos, fueran o no de la clase senatorial, con personas que practicaban el lenocinio, prostitutas, las condenadas en juicio como adúlteras (adúlteras flagrantes) y artistas de teatro.

A nuestro juicio y ya, en tercer lugar, existió este tipo de impedimento al matrimonio romano legal en tiempos de Augusto en aquellos matrimonios entre un liberto y su patrona, o el liberto y la que hubiera sido uxor del patrono (o la hija del mismo), así como en las uniones estables o convivencia entre un ciudadano romano y una latina o peregrina carente de la civitas, o en los matrimonios entre un cives y la libertas. Asimismo, era nulo el matrimonio del interdicto y del demente por la falta de capacidad de obrar que existía en este tipo de unión e, igualmente, los hijos de familia requerían el consentimiento del pater para contraer matrimonio porque, en caso contrario, el matrimonio contraído sería nulo. En suma, hemos concluido este tipo de uniones asegurando que la carencia de conubium en aquellos supuestos regulados por primera vez con las leyes de Augusto, pasaron a ser considerados como impedimentos relativos y de carácter social durante la existencia del Derecho Romano postclásico, ya que estos siguieron en vigor hasta la época del emperador Constantino quien extendió la lista de mujeres con las que los senadores ( $u$ otros altos cargos dignatarios como los perfectissimi, duoviri municipales, o sacerdotes provinciales) no podían contraer matrimonio por su baja condición social, como por ejemplo, con una mujer liberta o de humilde nacimiento.

El segundo grupo de uniones extramaritales que pertenecían a este último criterio que nos sirve de cierre a nuestra clasificación, es el relativo a las relaciones sine conubio surgidas desde la Roma postclásica por la influencia del Cristianismo. Observamos a las uniones ilícitas entre tutor y pupila ${ }^{36}$ resaltando expresamente que, de acuerdo a un Senadoconsulto de los tiempos de Marco Aurelio y Cómodo (175 y 180 d.C.), se prohibió el matrimonio entre tutor y pupila antes de rendir cuenta sobre la administración de sus bienes y en tanto que no se extinguiese el plazo para intentar una restitutio in integrum por la minoría de edad, de forma que el impedimento se extendía también al pater del tutor y a sus descendientes. Respecto a la evolución jurídica de este supuesto, desde época postclásica, esta prohibición se extendió a los hijos y nietos del tutor, los hijos adoptivos de éste siempre que estuvieran bajo su potestad, el

${ }^{36}$ BORRELLI, P., "Il divieto di matrimonio tra tutore e pupilla", LABEO, XLIII (1997), pp. 365389. 
padre del tutor y sus herederos aunque fuesen extraños, pues se creía que todos ellos conformaban uniones carentes de conubium por razón del cargo público del tutor ${ }^{37}$.

De la misma manera, el rapto se configuró como una limitación matrimonial introducida en la etapa postclásica a causa del arrebato de una doncella núbil, casada o viuda, sin su previo consentimiento o el de sus padres, aunque ya la Lex lulia de adulteriis coercendis había prohibido el matrimonio entre el raptor y mujer raptada, según la propia romanística ${ }^{38}$. Sobre las uniones con colonos de baja condición social, por su parte, decir que si bien los denominados impedimentos matrimoniales por colonato se regularon específicamente en Roma a partir del emperador Justiniano, lo cierto es que desde época postclásica comenzaron a surgir las denominadas uniones extramatrimoniales por impedimento de colonato entre una mujer libre y un colono ajeno (coloni adscripticii o servi glebae); pero, como O. Robleda ${ }^{39}$ nos recuerda, tal prohibición sólo era aplicada a los colonus pero no a los esclavos, ya que al esclavo no se le prohibía el matrimonio.

En cuanto a la disparidad de religión entre judíos y cristianos, subrayar que hasta la Roma clásica las creencias religiosas no supusieron un impedimento para no celebrar el iustum matrimonium ya que se tenía una especial tolerancia por los cultos de los pueblos extranjeros, de tal modo que muchos de ellos los practicaban; resultando muy común, a comienzos de la época imperial, el hecho de que las mujeres romanas se sintieran atraídas por los cultos en adoración a la diosa egipcia Isis. No obstante, las persecuciones en contra de los cristianos tuvieron un motivo político más que religioso porque atentaban a las costumbres romanas por ir en contra de la esclavitud y por no prestar adoración a la figura del emperador, el cual, era considerado como una divinidad al igual que lo eran los dioses. Así, la diversidad de religión desde la etapa postclásica pasó a conformarse como una verdadera limitación al matrimonio iustum dadas las luchas políticas e ideológicas entre judíos y cristianos, motivo por el cual, los cristianos no pudieron contraer matrimonio con personas de otra religión o culto y, en caso de hacerlo, se conformaban como uniones extramatrimoniales sine conubio por disparidad de religión entre estos, y tal tipo de unión perduró hasta la etapa de Justiniano quien en el año 556 d.C. suprimió la pena capital de la adúltera por la pena de la vida monástica.

En línea con los casos analizados, el parentesco espiritual o religioso también impidió el matrimonio en época del emperador Justiniano, dada la relación existente entre las partes ${ }^{40}$; con la llegada del Cristianismo al Imperio no podían ser un matrimonio romano legal y, formaban parte de las calificadas de uniones sine conubio, las relaciones entre el padrino y la ahijada dado el vínculo establecido por el bautismo entre el bautizado y sus padrinos y madrinas, a pesar de que se podían unir maritalmente madrina y ahijado. Por último, se ha abordado la naturaleza de este tipo de impedimento por cognación espiritual, admitiéndose que fue el emperador Justiniano el primero que lo configuró como matrimonio sacrílego e incestuoso teniéndolo por no celebrados, por lo que los hijos habidos en tales uniones adquirían la consideración de espurios (spurii) o lo que hoy se conoce como bastardos.

Para completar lo anterior, hacemos una breve alusión al orden sagrado y al voto de castidad como límites matrimoniales. En efecto, dentro de esta última tipificación se encuadran aquellas uniones sine conubio que Justiniano prohibió que se denominasen como matrimonium dado el orden sagrado (los cuerpos constituidos en sentido civil, es decir, el cuerpo de los que gobernaban) o el voto de castidad (simbolizaba la renuncia abierta a una vida marital con otra persona y el no tener relaciones sexuales por el voto público y solemne contraído con la institución religiosa). Si bien es cierto que ya desde tiempo postclásico se había ido reconociendo progresivamente dicha limitación, no fue hasta el año 531 d.C. cuando

${ }^{37}$ Cfr. D. 23,1,15 (Mod. libr. sing. de enucleatis casibus); Cfr. D. 23,2,36 (Paul. 5 quaest.); Cfr. D. 23,2,37 (Paul. 7 resp.); Cfr. D. 23,2,59 (Paul libr. sing. de assignat. libert.); Cfr. D. 23,2,60,5 (Paul. libr. sing. ad orat. divi Antonini et Commodi); Cfr. D. 23,2,64,1 (Callist. 2 quaest.); Cfr. D. 23,2,67,3 (Thryph. 9 disputat.); Cfr. D. 23,2,67,4 (Thryph. 9 disputat.).

${ }^{38}$ Con relación al rapto y la Lex Iulia de adulteriis, vid. por todos, BIONDI, B., II Diritto Romano cristiano..., op. cit., p. 93 ss.; ROBLEDA, O., El matrimonio en Derecho Romano..., op. cit., p. 209.

${ }^{39}$ ROBLEDA, O., El matrimonio en Derecho Romano..., op. cit., p. 276.

${ }^{40}$ Cfr. CJ. 5,4,26,2. 
Justiniano ${ }^{41}$ expresamente declaró que, tanto el orden sagrado como el voto de castidad, se conformaban como impedimentos matrimoniales en los que el emperador aplicó la doctrina canónica al Derecho Romano.

\section{CONCLUSIONES}

A modo de conclusión, finalizamos nuestra exposición afirmando que la escasez de estudios que tradicionalmente han abordado de una forma sistemática e íntegra la diversidad de uniones extramatrimoniales o relaciones esporádicas reconocidas por el propio Derecho Romano han justificado la elaboración del presente trabajo. Por tal razón, entendemos que una mera lectura del título del mismo, esto es: "Perspectiva evolutiva de las tradicionales uniones de hecho e intersexuales desde Roma", nos lleva a reparar en las diferencias que presentaba en época clásica el iustum matrimonio y con plenos efectos, respecto a aquellas otras numerosas parejas ilegítimas surgidas durante la etapa de mayor esplendor del Imperio por no cumplir con los presupuestos esenciales exigidos legalmente; destacando, en este punto, la carencia del requisito de la capacidad física, la inexistencia del conubium o capacidad jurídica de las partes, así como la falta de un consentimiento mutuo y continuado entre los que se unían libremente en un consorcio para toda la vida, tal y como las escasas o fragmentarias fuentes con las que contamos establecen a la hora de delimitar El matrimonio romano ${ }^{42 .}$

Ante la inexistencia de una clasificación doctrinal más o menos homogénea que aglutine tal diversidad de parejas de hecho, pues como se ha demostrado algunas meramente se limitan a enumerarlas sin seguir un criterio fijo 0 estructurado ${ }^{43}$, hemos visto necesario agrupar las cerca de treinta uniones sexuales sine conubio existentes desde la antigüedad romana bajo seis criterios o principios que, a nuestro parecer, por primera vez clasifican e integran de forma innovadora estas relaciones tan frecuentes; diferenciándose, específicamente, entre los siguientes supuestos: a) según el criterio de de la consideración jurídico-social de los que se unen ilícitamente ${ }^{44}$, distinguiendo entre el concubinato, contubernio, homosexualidad ${ }^{45}$, uniones con patricios y plebeyos, matrimonios contra mandata, con persona deportada a una isla 0 ausente por cumplir con el servicio militar; b) bajo el principio de la capacidad física o natural de las partes, se encuadran los casos de relaciones sine conubio con castrados, esterilizados, impotentes o ancianos, y con sujetos que presentaran falta de capacidad mental o demencia; c) conforme a los vínculos familiares existentes, cabría citar las uniones extra-conyugales por incesto, ligamen, consanguinidad, o aquellas donde la viuda no hubiese respetado el tiempo de luto marcado por el Derecho Romano para evitar mezcla de sangres; d) en lo que alude al criterio que tiene en cuenta la existencia de

\footnotetext{
${ }^{41}$ Cfr. CJ. 1,3,52,14.

${ }^{42}$ Cfr. D. 23,2,1 (Mod. 1 reg.); Cfr. IJ. 1,9,1.

${ }^{43}$ GHIRARDI, J. C., "Regulación jurídica de las conductas sexuales...", op. cit., p. 9 ss.

${ }^{44}$ DE ROBERTIS, F. M., "La condizione sociale e gli impedimenti...", op. cit., p. 45 ss.

${ }^{45}$ MUÑOZ CATALÁN, E., "La impotencia generandi...", op. cit.
} 
consentimiento, reunimos a los matrimonios simulados, por miedo o aquellos matrimonios informes; e) sobre el respeto o no al matrimonio monogámico y los principios de la moral romana, se diferencia entre uniones de facto, adulterio, prostitución o lenocinio; f) finalmente, según el pensamiento de los emperadores, cabe citar aquellas relaciones prohibidas por Augusto por ir contra de su legislación matrimonial, como las uniones entre senadores y mujeres turpes, y aquellas otras limitadas por los emperadores cristianos Constantino y Justiniano, como por ejemplo las uniones bajo parentesco espiritual, orden sagrado o voto de castidad.

A lo anterior cabría añadir, en último término, un nuevo vínculo sexual surgido desde la primitiva Roma bajo el término originario de hermafrodita, pero que hoy se presenta como sinónimo intersexual; nos estamos refiriendo a aquellas uniones extramatrimoniales sine conubio presentes en el Imperio y llevadas a cabo entre sujetos con cierta ambigüedad genital o malformaciones, las cuales, podríamos agrupar tanto en el primer criterio que hemos defendido previamente relativo a la consideración jurídico- social de los que se unen, como en el segundo principio que hemos manejado para concretar aquellas otras relaciones en las que al menos uno de los cónyuges carecía de la capacidad física o natural exigida para el matrimonio legal. La razón de su estudio, no es otra, que el reciente y progresivo reconocimiento legal que están teniendo desde los distintos Ordenamientos jurídicos europeos aquellas uniones con sujetos intersexuales, es decir, aquellas personas que como hemos definido desde el comienzo de nuestro trabajo, desde un punto de vista biológico y médico, presentan un tercer sexo, un sexo indefinido, un trastorno del desarrollo sexual, genitales ambiguos ${ }^{46}$ o, en general, cuerpos sexuados ${ }^{47}$.

Por lo que desde principios de Noviembre de 2013 y, gracias a la nueva normativa aprobada por Alemania en esta materia, Europa cuenta ya con precedentes que paulatinamente van a ayudar a romper desde los distintos países miembros con las barreras que ancestralmente han rodeado a estos seres humanos, al no existir hasta ahora una definición jurídica expresa que regulara los derechos de los sujetos que nacieran con una ambigüedad genital o con anomalías congénitas que le impidieran el normal desarrollo de los órganos sexuales femeninos y masculinos. Lo que, sin duda, tendrá su repercusión en unos meses en España para tratar de adaptar la legislación matrimonial a la realidad social que nos rodea pues, como ya advirtiera $P$. Panero $^{48}$, desde la reforma introducida con la aprobación de la Ley $13 / 2005$, de 1 de julio, por la que se modifica el Código Civil en materia de derecho a contraer matrimonio, se ha extendido una nueva terminología en nuestro Ordenamiento jurídico español que incluye otras relaciones frecuentes surgidas de forma paralela al matrimonio, concretamente nos estamos refiriendo a las parejas de hecho, las uniones libres, la convivencia more uxorio o igualmente

\footnotetext{
${ }^{46}$ AGRAMONTE MACHADO, A., "Tratamiento quirúrgico de los genitales ambiguos...", op. cit.; UGARTE, F. y SEPÚLVEDA, C., "Estudio del recién nacido con ambigüedad genital...", op. cit., pp. 578-583.

${ }^{47}$ FAUSTO STERLING, A., Cuerpos sexuados. La política de género y la construcción de la sexualidad, Barcelona, 2006.

${ }^{48}$ PANERO ORIA, P., "El concubinato romano como antecedente de las actuales parejas de hecho", RIDROM, V (2010), pp. 92-125.
} 
incluimos las hoy conocidas como parejas intersexuales, en los términos que hemos venido definiendo.

En suma, podemos concluir afirmando que desde el año 2005 el legislador español ha sido consciente de las transformaciones que están rodeando a la familia y especialmente en lo que se refiere al matrimonio, favoreciendo un marco legislativo en el que no quepa discriminación alguna por razón de sexo o género. $Y$ muestra de ese deseo por adaptarse a la realidad social es cómo comienza su exposición la citada ley, cuando literalmente se recuerda que: "Tampoco en forma alguna cabe al legislador ignorar lo evidente: que la sociedad evoluciona en el modo de conformar y reconocer los diversos modelos de convivencia, y que, por ello, el legislador puede, incluso debe, actuar en consecuencia, y evitar toda quiebra entre el Derecho y los valores de la sociedad cuyas relaciones ha de regular (...). La convivencia como pareja entre personas del mismo sexo basada en la afectividad ha sido objeto de reconocimiento y aceptación social creciente, y ha superado arraigados prejuicios y estigmatizaciones. Se admite hoy sin dificultad que esta convivencia en pareja es un medio a través del cual se desarrolla la personalidad de un amplio número de personas, convivencia mediante la cual se prestan entre sí apoyo emocional y económico, sin más trascendencia que la que tiene lugar en una estricta relación privada, dada su, hasta ahora, falta de reconocimiento formal por el Derecho". Aceptándose que esta percepción innovadora no sólo se produce en la sociedad española de comienzos del siglo $\mathrm{XXI}$, sino también en ámbitos más amplios y desde décadas anteriores, como se refleja en la Resolución del Parlamento Europeo, de 8 de febrero de 1994, en la que ya desde entonces se solicitaba formalmente a la Comisión Europea que presentase una propuesta de recomendación para tratar de poner fin a la prohibición de contraer matrimonio a las parejas del mismo sexo, garantizándoles plenos derechos y también los beneficios asignados al matrimonio.

\section{REFERENCIAS BIBLIOGRÁFICAS}

(2006) AGRAMONTE MACHADO, A., "Tratamiento quirúrgico de los genitales ambiguos: fundamentos e implicaciones psicológicas y sexuales", Revista Cubana de Endocrinología, v. 17, III [En línea]: http://scielo.sld.cu/scielo.php?script=sci_arttext\&pid=S156129532006000300004

(2006) ASTOLFI, R., II matrimonio nel Diritto Romano classico, Editorial CEDAM, Padova.

(1954) BIONDI, B., II Diritto Romano cristiano III, Giuffrè Editore, Milano.

(1997) BORRELLI, P., "II divieto di matrimonio tra tutore e pupilla", LABEO, XLIII, pp. 365-389.

(1998) BRAVO BOSCH, M. J., "Algunas consideraciones sobre el Edictum de Adtemptata ad pudicitia", en AAVV., Actas del Il Congreso Iberoamericano de Derecho Romano, Editorial Servicio de Publicaciones de la Universidad de Murcia, Murcia, pp. 41-53. 
(2004) CUENA BOY, F., "La prohibición del funcionario con mujer de la provincia en la que sirve. Derecho Romano y Derecho castellano", en LÓPEZROSA, R. y DEL PINO-TOSCANO, F. (Eds.), El Derecho de Familia. De Roma al Derecho Actual, Editorial Servicio de Publicaciones de la Universidad de Huelva, Huelva, pp. 99-108.

(1978) DANILO DALLA, L., "L'Incapacità sessuale in Diritto Romano", en Seminario giuridico della Università di Bologna, LXXVI, Giuffrè Editore, Milano.

(1999) DELAPUERTA MONTOYA, D., Estudio sobre el Edictum de Adtemptata Pudicitia, Editorial Tirant Lo Blanch, Valencia.

(1939) DE ROBERTIS, F. M., "La condizione sociale e gli impedimenti al matrimonio nel Basso Imperio", Annali Bari, IV, pp. 45-69.

(1973) M. FALÇAO, Las prohibiciones matrimoniales de carácter social en el Imperio Romano, Editorial Servicio de Publicaciones de la Universidad de Navarra, Navarra.

(2006) FAUSTO STERLING, A., Cuerpos sexuados. La política de género y la construcción de la sexualidad, Editorial Melusina, Barcelona.

(2005) GHIRARDI, J. C., "Regulación jurídica de las conductas sexuales extramatrimoniales en el Derecho Romano", RGDR, V, pp. 1-49.

(1983) LILJA, S., Homosexuality in Republican and Augustan Rome, Editorial Societas Scientiarum Fennica, Helsinki.

(2005) MARTÍNEZ DE MORENTÍN LLAMAS, M. L., "De la cura furiosi en las XII Tablas, a la protección del disminuido psíquico en el Derecho Actual (A propósito de la STS de 20 de noviembre de 2002)", RGDR, IV, pp. 1-66.

(2013) MUÑOZ CATALÁN, E., "Las uniones extramatrimoniales ante la falta de conubium: Fundamento jurídico de los impedimentos matrimoniales en la Roma clásica", en Arias Montano: Repositorio institucional de la Universidad de Huelva. Colección de Tesis Doctorales, pp. 338-736 [En línea]: http://rabida.uhu.es/dspace/bitstream/handle/10272/6457/Las_uniones_extrama trimoniales.pdf?sequence $=2$

(2013) MUÑOZ CATALÁN, E., "La impotencia generandi en el matrimonio romano homosexual", FORO. Revista de Ciencias Jurídicas y Sociales, Nueva Época , vol 16, II linn http://revistas.ucm.es/index.php/FORO/issue/current

(1970) ROBLEDA, O., El matrimonio en Derecho Romano. Esencia, requisitos de validez, efectos, disolubilidad, Librería Editrice Università Gregoriana, Roma.

(2010) PANERO ORIA, P., "EI concubinato romano como antecedente de las actuales parejas de hecho", RIDROM, V, pp. 92-125.

(1960) SCHULZ, F., Derecho Romano clásico, Bosch Casa Editorial, Barcelona.

(2007) UGARTE, F. y SEPÚLVEDA, C., "Estudio del recién nacido con ambigüedad genital y gónadas palpables", Revista Chilena de pediatría, v. 78, VI, pp. 578-583 [En línea]: http://www.scielo.cl/pdf/rcp/v78n6/art02.pdf

(2014) CÓDIGO CIVIL ESPAÑOL (Edición vigente hasta el 22 de Julio de 2014) [En línea]: http://noticias.juridicas.com/base_datos/Privado/cc.html 
(2014) LEY 13/2005, DE 1 DE JULIO, POR LA QUE SE MODIFICA EL CÓDIGO CIVIL EN MATERIA DE DERECHO A CONTRAER MATRIMONIO [En línea]: http://www.boe.es/boe/dias/2005/07/02/pdfs/A23632-23634.pdf (2014) TEXTOS JURÍDICOS DE DERECHO ROMANO [En línea]: http://bib.us.es/derecho/recursos/pixelegis/areas/derechoRomano-idesidweb.html 